\title{
THE MULTIDRUG RESISTANCE AND APOPTOSIS EVALUATION IN ACUTE MYELOID LEUKEMIA CELLS AFTER THE IN VITRO DOXORUBICIN TREATMENT
}

\author{
Karolína Jankovičová ${ }^{1}$, Jan Krejsek ${ }^{1}$, Otakar Kopecký ${ }^{1}$, Jaroslava Voglová2 ${ }^{2}$ Zuzana Škrabková ${ }^{3}$, Jakub Novosad
}

Charles University in Prague, Faculty of Medicine and University Hospital in Hradec Králové, Czech Republic: Department of Clinical Immunology and Allergology ${ }^{1}$, Department of Clinical Hematology ${ }^{2}$, Department of Medical Biophysics ${ }^{3}$

Summary: The apoptosis failure in cytostatic treatment of haemoblastosis is one of the means of chemoresistance. We were interested in the relationship of the after-doxorubicin-treatment-AML cells apoptosis and the immunophenotype, selected clinical and laboratory parameters, and also the P-gp, MRP, LRP, Bcl-2, Bax proteins expression. All analysis were evaluated with the flow cytometry method. To detect apoptotic cells in the sample, we used three methods: annexin test, TUNEL (TdT-mediated dUTP nick end labeling) test, and caspase 8 detection. After the cell cultivation the statisticaly important increase of apoptotic cells in the culture was apparent. The relation between the AML blast in vitro reaction and some clinical parameters such as the age of patient, white blood cell count, and blast percentage was also observed.

Key words: AML; Apoptosis; Multidrug resistance; Flow cytometry

\section{Introduction}

The multidrug resistance of cancer cells is usually considered as one of the most important problems complicating chemotherapy (1). It seems that the multidrug resistance is a more common type of the resistance to cytostatics (10) and is the mostly studied topic of the cancer research in the last three decades (13).

The chemoresistance is often associated with the presence of proteins decreasing the intracellular drug concentration such as P-gp, MRP, and LRP proteins. P-gp (P-glycoprotein) and MRP (multidrug resistance associated protein) belong to the ABC (ATP-binding cassette) transporter proteins which are present in cell membranes. They act as the pumps changing the drug concentration in the cell. LRP (lung resistance protein) is a member of human vault protein family and participates in the drug sequestration into the cell vesicles $(1,13)$.

The changes in apoptotic process which disable the cell death, as it is usual in the treatment with cytostatics, is another important issue in the area of chemoresistance (15). The key role in the apoptosis plays the cystein proteases - caspases system which has about 10 enzymes interacting with other apopotic factors and being active in the proteolytic cascade which ends with the degradation of all life important cell structures such as DNA, intracellular enzymes, and structural proteins (5). Bcl-2, Bax and other similar proteins play an important role in the apoptotic process (21). They have either proapoptotic (Bax, Bad, Bak, Bik, Bid, Hrk, Bcl-X ${ }_{S}$ ) or antiapoptotic (Bcl-2, Bcl-X ${ }_{L}$, Mcl-1, A1/BFL-1, Bcl-W) effects. The overexpression of the antiapoptotic members of the Bcl-2 protein family often induce chemoresistance due to the apoptosis disability (14).

There are three key points of the apoptosis towards which many cell processes and methods of apoptosis evaluation are related. They are: the chromatin condensation (DNA fragmentation detected with the TUNEL test), the mitochondria membrane potential breakdown, and plasma membrane changes (fosfatidylserin detection by the annexin test) (19). Caspases and Bcl-2 protein family members are also often examined in many studies. The leukemic cells cultivation with cytostatics help to predict the effectivness of the treatment (4).

\section{Material and methods}

\section{Patients}

Thirty five patients with AML, 16 men and 19 women with an average age 62 years, were enrolled in this study. This study was approved by the institutional ethical committee. Written consent of every patient was obtained. We cooperated with the Hematology Department of the Faculty Hospital in Hradec Králové and other hematology departments in our region. 


\section{Samples}

Samples of the heparinized peripheral blood and bone marrow were used for the analysis. Mononuclear cells separated by the density gradient centrifugation (Lymphoprep $^{\mathrm{TM}}$, Nyegaard \& Co. A/S) were used for the indirect immunofluorescence.

Detection of "multidrug resistance associated" proteins P-gp protein was detected by the direct immunofluorescence with UIC2-PE monoclonal antibody (Immunotech). Another P-gp detection was performed by indirect immunofluorescence with MRK16 monoclonal antibody (Kamiya Biomedical Company). Before MRP, LRP, Bcl-2 and Bax protein labeling permeabilization by IntraPrep ${ }^{\mathrm{TM}}$ Permeabilization Reagent (Immunotech) was performed. MRP protein was detected with MRPrl monoclonal antibody (Monosan) by indirect immunofluorescence, LRP protein was detected with LRP-56 monoclonal antibody (Monosan) by indirect immunofluorescence, Bcl-2 protein was detected with Bcl-2/100 monoclonal antibody (PharMingen) by direct immunofluorescence and Bax protein was detected with 4F1 monoclonal antibody (Immunotech) by indirect immunofluorescence. Secondary labeling was carry out by PE-conjugated antibody $\left(\mathrm{F}\left(\mathrm{ab}^{\circ}\right) 2\right.$ anti IgG, Immunotech).

\section{Evaluation and controls}

The flow cytometry analysis was performed using Epics ${ }^{\circledR}$ XL (Beckman Coulter Company) equipment. The P-gp, MRP, LRP, Bcl-2 and Bax protein expression was measured according to the mean fluorescence intensity (MFI) of the gated cell population. The statistical analysis was realized with help of the NCSS 6.0.21 (1996) and STATISTICA 99 softwares.

\section{In vitro experiments with clinical samples}

Mononuclear cells of some patients were incubated in RPMI 1640 medium supplemented with the $10 \%$ fetal calf serum, gentamicin, and doxorubicin ( $1 \mu \mathrm{g} / \mathrm{ml}$, Sigma) at $37{ }^{\circ} \mathrm{C}$ and $5 \% \mathrm{CO}_{2}$ in $1 \times 10^{6} / \mathrm{ml}$ cell concentration. Each sample had three parallels - control, 22 hours, and 46 hours.

\section{Detection of apoptotic cells}

Annexin V - FITC test (Immunotech). It enables the distinguishing of three cell types: living cells (annexin $\mathrm{V}^{-} /$propidium iodidie (PI)-), apoptotic cells (annexin $\mathrm{V}^{+} / \mathrm{PI}^{-}$), and lately apoptotic - secondary necrotic cells (annexin $\mathrm{V}^{+} / \mathrm{PI}^{+}$).

Caspase 8 detection. The cell suspension $\left(5 \times 10^{5} / \mathrm{ml}\right)$ was permeabilized by IntraPrep ${ }^{\mathrm{TM}}$ Permeabilization Reagent (Immunotech) and subsequently incubated with 5F7 monoclonal antibody (Immunotech). Cells were labeled by the freshly diluted (1:20) secondary antibody conjugated with fluorescein isothiocyanate (anti-IgG, Biotest AG).

TUNEL test (TdT - mediated dUTP nick end labelling). The cell suspension ( $\left.5 \times 10^{5} / \mathrm{ml}\right)$ was fixed by $5,5 \%$ formaldehyde (Sigma) in PBS and permeabilized by $0,5 \%$ TWEEN 20 (Sigma) in PBS. The reaction mixture con- taining TdT buffer, FITC - conjugated dUTPs, and TdT (MEBSTAIN Apoptosis kit Direct, Immunotech) was incubated with permeabilized cells at $37{ }^{\circ} \mathrm{C}$ for 60 minutes. In the control sample TdT was omitted in the reaction mixture.

\section{Results}

\section{Comparison of in vitro experiments results}

The statistical analysis (ANOVA - Bonferroni test) showed following trends: The annexin test proved that number of apoptotic cells, secondary necrotic cells, and all dead cells increased in 22 hours of cultivation with doxorubicin. In the second interval - 46 hours - the increase in the dead cells continued but without the statistical significance. The caspase 8 detection did not prove the statisticaly significant change in the number of living cells after 22 hours of cultivation. In the 46 hours interval the number of apoptotic cells positive in caspase 8 even significantly decreased. The TUNEL test indicated increase of apototic cells in both intervals but without the statistical significance (Fig. 1).

2. Relation between CD34 expression and in vitro apoptosis

The analysis of CD34 expression and in vitro apoptosis showed certain trends but without the statistical significance. CD $34^{+}$blasts tended to be more resistant to the apoptosis induction. That was suggested by both annexin test and TUNEL test.
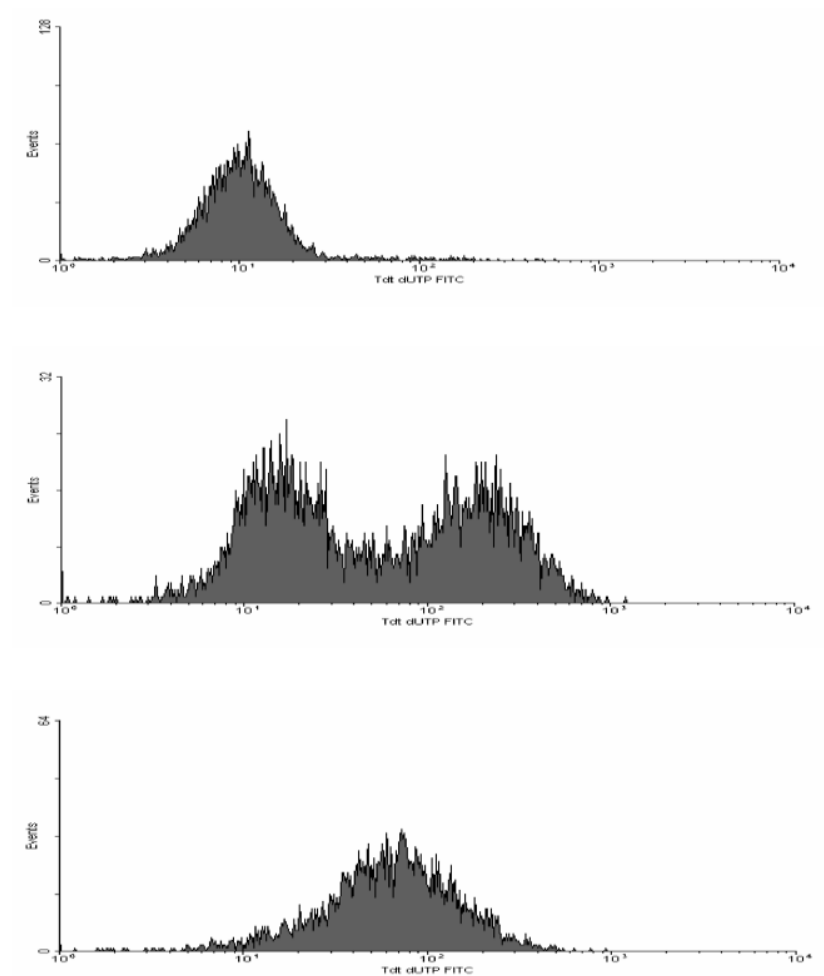

Fig. 1: TUNEL test detecting apoptotic AML cells after in vitro doxorubicin cultivation. The apoptotic cells percentage: control: $12 \%$, 22 hours: $42 \%$, 46 hours: $87 \%$. 


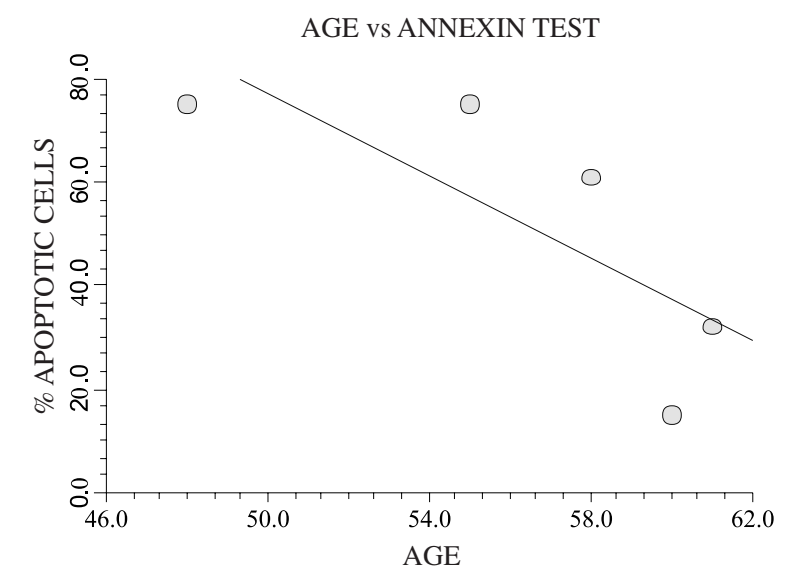

Fig. 2: Negative correlation between the age of AML patients and the number of apoptotic AML cells in annexin test after 46-hour cultivation with doxorubicin.

BAX vs MRP

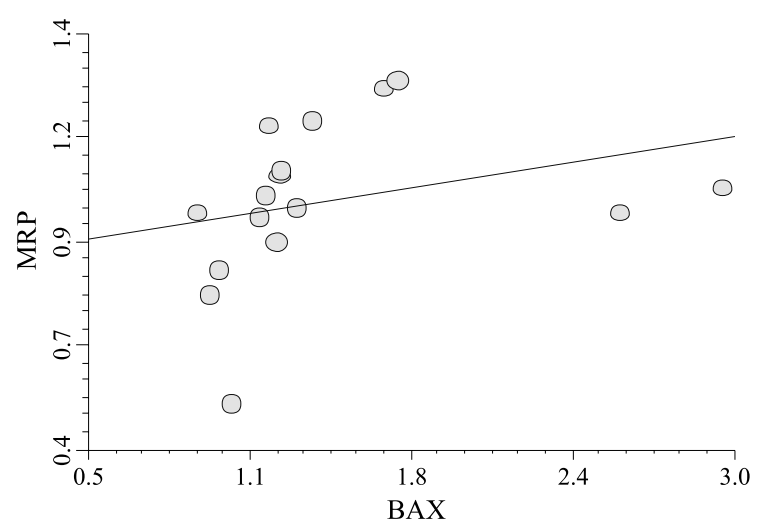

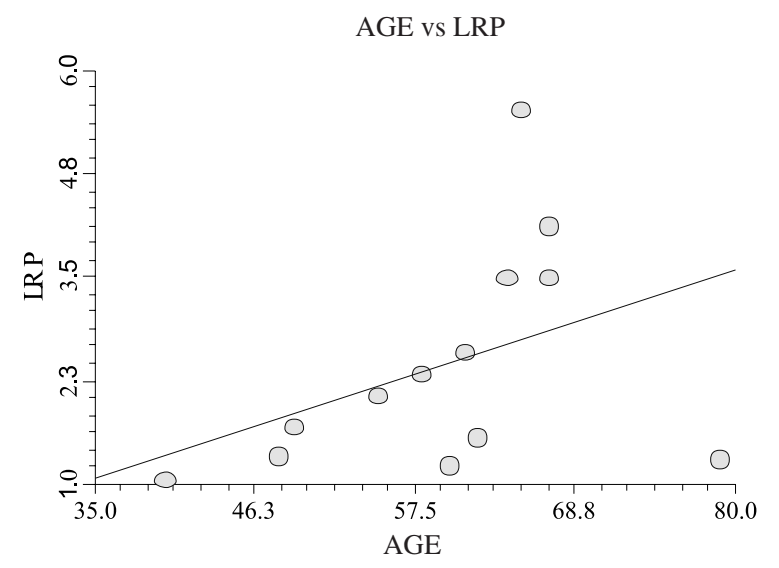

Fig. 3: Positive correlation between age of AML patients and the LRP protein expression.

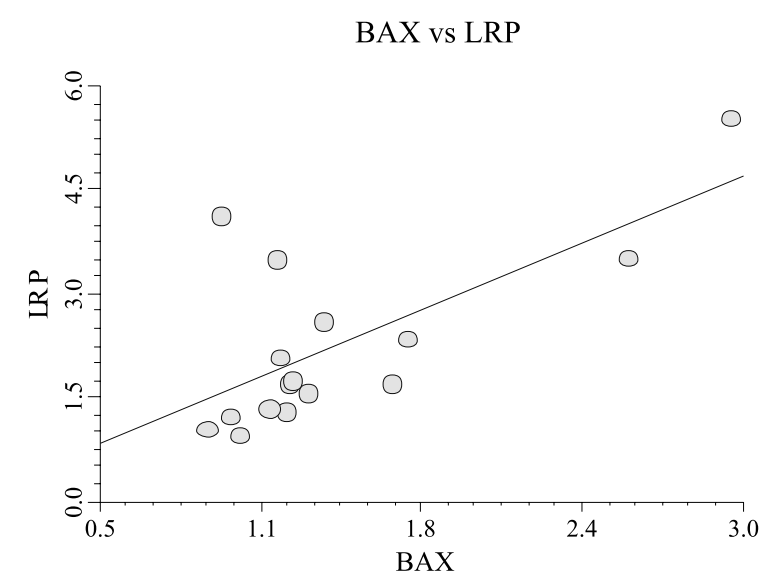

Fig. 4: Positive correlations between the Bax and MRP proteins expressions and between the Bax and LRP proteins expressions in AML patients.

\section{Relation between clinical parameters and in vitro} apoptosis

The statistically significant or nearly significant positive correlation between the age of patients and the caspase 8 expression $(p=0,054)$, between white blood cell count and the reaction in TUNEL test $(p=0,005)$, and furthermore between the blast percentage in blood and the reaction in TUNEL test $(p=0,005)$ in a 22-hour interval were found. In a 46-hour interval the positive correlation between the blast percentage in bone marrow and the number of apoptotic cells in annexin test $(p=0,037)$, and furthermore the nearly significant negative correlation between age of patients and the number of both apoptotic and lately apoptotic/secondary necrotic cells $(p=0,054)$ were found (Fig. 2 ).

\section{Relation between multidrug resistance markers expres-} sion and clinical parameters

The significant or nearly significant positive correlation between the P-gp expression detected by MRK16 monoclo- nal antibody and blast percentage in blood ( $\mathrm{p}=0,015)$, between the LRP expression and age of patients $(p=0,062)$ (Fig. 3), between the Bcl-2 expression and blast percentage in blood $(\mathrm{p}=0,041)$, and between the Bcl-2 expression and blast percentage in bone marrow $(p=0,016)$ were found.

\section{Relation between multidrug resistance markers}

The statistically significant positive correlation between the MRP and Bax expression ( $p=0,006)$, and furthermore, between the LRP and Bax expression $(p=0,034)$ were found (Fig. 4).

\section{Discussion}

We used cultivation tests of AML cells with doxorubicin for in vitro simulation of the cytostatic activity in leukemic cells. In most of the samples number of apoptotic cells rapidly increased after 22 hours of cultivation with cytostatics (measured with annexin test); however, during 
the next interval the changes were not statistically significant. Both other tests performed, either caspase 8 or TUNEL test, did not prove an increase in number of apoptotic cells in the cell culture. The results of caspase 8 test were even totally in contrary. Although, it is possible that caspase 8 play not a role in apoptosis of these blasts. According to Filipits et al. AML may be considered as the model for the study of the resistance to cytostatics (6). It has been already published that the spontaneous apoptosis of AML cells shows a significant correlation to the induction chemotherapy response (21). Although, from the analysis of the reaction of the myeloid cells in the culture, it was found that the lack of antiapoptotic cytokines can increase in vitro sensitivity to daunorubicin and thus make false positive results (4).

When analyzing the cultivation tests results, we managed to focus also on the blast phenotype. Because the number of samples was too small and in other markers less numerous, we can only presume a certain correlation to CD34 marker. In consistence with the studies published, it was indicated with TUNEL test and annexin test that CD $34^{+}$cells are more resistant to induction of apoptosis, though no statistical significance was reached. The similar results were published by Suarez et al. who presented that the unmature CD $34^{+}$AML blasts show higher Bcl-2 levels on the contrary to the mature CD 34- AML blasts in their work (16).

We gathered also some clinical data and we were interested in their significance to the in vitro blast apoptosis. Negative correlation between an age of patients and reaction in annexin test after 46 hours was found. This correlation leads us to the assumption that with the growing age of patients the resistance to apoptosis in AML increases and the prognosis is thus getting worse. Some other correlations having positive significance are still unexplained.

In some patients we tried to find the relation between some multidrug resistance markers and some clinical and laboratory data. These data are often used as the positive or negative prognostic markers. We found the weak positive correlation between the $\mathrm{Bcl}-2$ presence and blast percentage in both, blood and bone marrow, and the stronger positive correlation between the P-gp protein expression and blast percentage in blood. To a certain extent, the positive correlation between LRP phenotype presence and age of patients was showed. This result is in accordance with the conclusion of the Legrand et al. study and the Filipits et al. study, where it was proved that the level of LRP expression correlates with negative prognostic markers in AML such as age and karyotype (6) but there was not detected any correlation with other markers such as white blood cell count (9). On the contrary with this Burnett et al. found that LRP expression in AML patients is associated with the high white blood cell count and that it also correlates with favourable cytogenetics. They also published that the chemoresistance itself is less often seen in young patients (2). The studies on the P-gp protein discovered that the $\mathrm{P}$-gp expression is prognostically much more established in the group of AML patients who are over 55 years old (20) and in the older patients the P-gp expression is also more frequent (11). The so called "good karyotype" in AML is more often associated with the P-gp" and LRP- cases (12). This tendency was confirmed by Del Poeta et al. who proved the dependance of CD34, TdT and P-gp expression on the cytogenetic abnormalities and poor prognosis of AML (3). The tendency to decrease with the growing age of patients with AML was found in MRP protein (2).

The statistical analysis of multidrug resistance markers in AML proved the significant positive correlations between the MRP and Bax expression and also between the LRP and Bax expression. List et al. described the coexpression of P-gp and LRP in $31 \%$ of the AML cases and this coexpression was found as a strong negative prognostic factor in AML (18). Another correlation was found in the unmature AML cases between the P-gp and $\mathrm{Bcl}-2$ expression (21). The analysis of P-gp, MRP, Bcl-2, mutant p53 and hsp27 in AML revealed that coexpression of any of the two markers from this category correlates with the poor prognosis (8).

The new possibilities open for the future in this area given especially by the new discoveries in the study of apoptosis and also multidrug resistance as well. There are a lot of therapeutic applications rising from the activation of apoptosis in the leukemic cells. Great hope is put into the peptids imitating proapoptotic effect of $\mathrm{BH} 3$ domains of the $\mathrm{Bcl}-2$ family proteins and apoptosis inductors which are able directly activate caspases $(15,17)$. Molecular discoveries in the multidrug resistance area revealed many transport protein genes, new membrane pump modulators, apoptosis activators, new laboratory possibilities such as fluorescent substrates, monoclonal antibodies and new technical inventions (13). To date, we have not been successful in overcoming leukemic-cell drug resistance in a clinically significant way for the majority of AML patients. It seems that it is neccessary to target more than one mechanism responsible for the multidrug resistance (7).

\section{Conclusions}

The laboratory methodology to multidrug resistance markers detection was introduced. Some relations between multidrug resistance markers playing role in acute myeloid leukemia patients prognosis were suggested.

Supported by the Grant No. M/20-3/98 from Grant Agency, Ministry of Health, Czech Republic.

\section{References}

1. Arceci RJ. Can multidrug resistance mechanisms be modified? Br J Haemato 2000;110:285-91.

2. Burnett AK, Kell J, and Rowntree C. Acute myeloid leukemia: therapeutic indications. Curr Opin Hematol 2000;7:333-8.

3. Del Poeta G, Venditti A, Stasi R. et al. P-glycoprotein and terminal transferase expression identify prognostic subsets within cytogenetic risk classes in acute myeloid leukemia. Leuk Res 1999;23:451-65. 
4. Efferth T, Fabry U, Osieka R. Apoptosis and resistance to daunorubicin in human leukemic cells. Lekemia 1997:11:1180-6.

5. Elkon KB. Caspases: Multifunctional proteases. J Exp Med 1999;190:1725-7.

6. Filipits M, Stranzl T, Pohl G et al. Drug resistance factors in acute myeloid leukemia: a comparative analysis. Leukemia 2000;14:68-76.

7. Karp JE and Mookerjee BP. Overcoming drug resistance: targeting more than on site. Leuk Res 2002;26:107-9.

8. Kasimir-Bauer $\mathrm{S}$, Ottinger $\mathrm{H}$, Meusers $\mathrm{P}$ et al. In acute myloid leukemia, coexpression of at least two proteins, including P-glycoprotein, the multidrug resistance-related protein, bcl-2, mutant $\mathrm{p} 53$, and heat-shock protein 27 , is predictive of the response to induction chemotherapy. Exp Hematol 1998;26:1111-7.

9. Legrand O, Simonin G, Zittoun R, Marie JP. Lung resistance protein (LRP) gene expression in adult acute myeloid leukemia: a critical evaluation by three techniques. Leukemia 1998;12:1367-4.

10. Legrand O, Zittoun R, Marie JP. Role of MRP1 in multidrug resistance in acute myeloid leukemia. Leukemia 1999;13:578-84.

11. Leith CP, Kopecky KJ, Godwin J et al. Acute myeloid leukemia in the elderly: assessment of multidrug resistance $(\mathrm{mdr} 1)$ and cytogenetics distinguishes biologic subgroups with remarkably distinct responses to standard chemotherapy. A Southwest Oncology Group Study. Blood 1997;89:3323-9.

12. Michieli M, Damiani D, Ermacora A et al. P-glycoprotein, lung resistance-related protein and multidrug resistance associated protein in de novo acute non-lymphocytic leukaemias: biological and clinical implications. Br J Haematol 1999; 104:328-35.

13. Ramachandran $\mathrm{Ch}$ and Melnick SJ. Multidrug resistance in human tumors - molecular diagnosis and clinical significance. Mol Diagnosis 1999;4:81-94.

14. Reed JC. Bcl-2 family protein and mechanisms of chemoresistance in lymphomas and leukemias. Adv Leuk Lymph 1995;5:3-11.

15. Sellers WR, Fisher DE. Apoptosis and cancer drug targeting. J Clin Invest 1999; 104:1655-61.

16. Suarez L, Vidriales B, Garcia-Larana J et al. Multiparametric analysis of apoptotic and multi-drug resistance phenotypes according to the blast cell maturation stage in elderly patients with acute myeloid leukemia. Haematologica 2001; $86: 1287-95$

17. Tolomeo M, Grimaudo S, Milano S et al. Effects of chemically modified tetracyclines (CMTs) in sensitive, multidrug resistant and apoptosis resistant leukaemia cell lines. Br J Pharmacol 2002;135:1588.

18. Tsuji K, Motoji T, Sugawara I et al. Significance of lung resistance-related protein in the clinical outcome of acute leukaemic patients with reference to P-glycoprotein. Br J Haematol 2000;110:370-8.

19. Vermes I, Haanen C, Richel DJ, Schaafsma MR, Kalsbeek-Batenburg E. and Reutelingsperger CPM. Apoptosis and secondary necrosis of lymphocytes in culture. Acta Haematol 1997;98:8-13.

20. Willman $\mathrm{Ch}$. The prognostic significance of the expression and function of multidrug resistance transporter proteins in acute myeloid leukemia: studies of the Southwest Oncology Group Leukemia Research Program. Sem Oncol 1997; 34(suppl 5):25-33.

21. Wuchter C, Karawajew L, Ruppert V et al. Clinical significance of CD95, Bcl-2 and Bax expression and CD95 function in adult de novo acute myeloid leukemia in context of P-glycoprotein function, maturation stage, and cytogenetics. Leukemia 1999;13:1943-53.

Submitted April 2004

Accepted May 2004.

Mgr. Karolína Jankovičová,

University Hospital in Hradec Králové,

Department of Clinical Immunology and Allergology,

50005 Hradec Králové,

Czech Republic.

e-mail: ukia@fnhk.cz 